\section{References}

Achord, J. L., and Gerle, R. D. (1966). Bone lesions in pancreatitis. American Journal of Digestive Diseases, 11, 453-459.

Miles, R. N. (1959). Pancreatic cyst in the newborn. Annals of Surgery, 149, 576-581.

Moossa, A. R. (1974). Pancreatic pseudocysts in children.
Journal of the Royal College of Surgeons of Edinburgh, 19, 149-158.

Shackleford, P. G. (1977). Osseous lesions and pancreatitis. American Journal of Diseases of Children, 131, 731-732.

Correspondence to $\mathrm{Dr}$ P. Hollingworth, Mathilda and Terence Kennedy Institute of Rheumatology, Bute Gardens, London W6 7DW.

\title{
Lumbar punctures, meningitis, and persisting pleocytosis
}

\section{KEVIN D. CONNOLLY}

\section{Children's Research Centre, Our Lady's Hospital for Sick Children, Dublin}

SUMMARY A retrospective survey of children with haemophilus and pneumococcal meningitis was carried out to assess the significance of persistent CSF pleocytosis and the need for repeat lumbar punctures after adequate treatment. Persistent pleocytosis was noted in 9 of 27 patients with haemophilus meningitis; this tended to be present in those with higher initial CSF white blood counts and lower initial CSF glucose contents. No sequelae were noted in those with persistent pleocytosis. Repeat lumbar punctures were not of clinical benefit and tended to result in longer treatment which was not warranted.

One criterion used to decide when to stop treatment in a child with bacterial meningitis is the presence of a CSF white blood count of $<0.050 \times 10^{9} / 1$ after 10-14 days of treatment (Smith et al., 1973). However, not only may a lumbar puncture be dangerous (Shinefield, 1975), but children who have received apparently adequate treatment can show persistent increases in the CSF white blood count. This survey was carried out to assess the significance of persistent pleocytosis and the need for a repeat lumbar puncture in a clinically well child after reasonable treatment.

\section{Patients and methods}

Records of all patients aged over 2 months admitted to this hospital between January 1972 and July 1977 with a diagnosis of bacterial meningitis were examined. The survey was confined to those who grew Haemophilus influenzae or Streptococcus pneumoniae from their CSF. Patients with recognised anatomical defects of skull or spine, those with immunological disorders, and those who did not have lumbar punctures repeated between days 10 and 14 were excluded. Those with meningococcal meningitis were also excluded as very few have persistent pleocytosis and their prognosis is better.
All those with $H$. influenzae received chloramphenicol for at least 10 days. In addition 22 received ampicillin for 10 days. 13 were given sulphonamide and 5 were given penicillin for varying periods. All with pneumococcal meningitis received penicillin for at least 10 days. In addition, 6 were given chloramphenicol, 6 were given sulphonamide, and 4 were given ampicillin for varying periods. Persistent pleocytosis was defined as a CSF white blood count $>0.050 \times 10^{9} / 1$ between days 10 and 14 .

37 babies fulfilling these criteria were examined with regard to organism, initial and repeat CSF findings, duration of pyrexia, and sequelae. The duration of follow-up was from $1 \frac{1}{2}$ to $5 \frac{1}{2}$ years. Full physical and neurological examination and clinical assessment of hearing were carried out when the patients were recalled.

\section{Results}

Of the 37 patients studied, $H$. influenzae was isolated from 27, and $S$. pneumoniae from 10 . Nine of the 37 had persistent pleocytosis and all of these grew $H$. influenzae. The initial CSF white blood counts in those with persistent pleocytosis tended to be higher if one excludes one baby with pneumococcal meningitis whose initial count was $64.0 \times 10^{9} / 1$ (Table). This patient's CSF cell count fell to

Table Comparison between patients with and without pleocytosis

\begin{tabular}{lll}
\hline & $\begin{array}{l}\text { With } \\
\text { pleocytosis }\end{array}$ & $\begin{array}{l}\text { Without } \\
\text { pleocytosis }\end{array}$ \\
\hline $\begin{array}{l}\text { Number } \\
\begin{array}{l}\text { Initial CSF WBC } \\
\quad \times 10^{9} / 1\end{array}\end{array}$ & 9 & 28 \\
$\begin{array}{l}\text { CSF cells } \\
\quad 5.0 \times 10^{9} / 1 \text { at } \\
\text { diagnosis }\end{array}$ & $5 \cdot 79$ & $3 \cdot 402^{*}$ \\
$\begin{array}{l}\text { Temperature }>37 \cdot 5^{\circ} \mathrm{C} \\
\quad \text { at day 5 }\end{array}$ & 7 & 7 \\
Sequelae & 5 & \\
\hline
\end{tabular}

*One patient with CSF WBC of $64.0 \times 10^{9} / 1$ is excluded. 
$0.024 \times 10^{9} / 1$ on day 11 , and no sequelae were noted. The initial counts between those with and those without pleocytosis overlapped. The initial mean CSF glucose content was appreciably lower in the pleocytosis group $(0.3$ compared with $1.9 \mathrm{mmol} / 1 ; 5.4$ compared with $34 \mathrm{mg} / 100 \mathrm{ml}$ ), but again the two groups overlapped. The initial CSF protein content was similar in the two groups.

Patients with persistent pleocytosis had more lumbar punctures performed ( 5 compared with 1$)$, were given antibiotics for a longer period ( 22 compared with 15 days), and spent longer in hospital (32 compared with 17 days), than those without pleocytosis. This prolonged time in hospital was due only to the abnormal CSF cell content. Temperatures were over $37 \cdot 5^{\circ} \mathrm{C}$ after 5 days of treatment in 5 of the 9 babies with persistent pleocytosis, but in only 3 of the 27 without such pleocytosis. Apart from persistent pyrexia, however, the clinical course was similar in the two groups. Relapse did not occur in any of the 37 babies. Eight of the 9 with pleocytosis were re-examined after $1 \frac{1}{2}$ to $5 \frac{1}{2}$ years. None had a residual neurological deficit or a clinically significant hearing loss. 19 of the 27 without persistent pleocytosis were seen after $1 \frac{1}{2}$ to $4 \frac{1}{2}$ years. Four of these 19 had long-term complications. One girl who had many convulsions during her meningitis has moderate mental handicap and a left hemiparesis. One has mild mental handicap. One has severe unilateral deafness. The 4th had ataxia which disappeared after 3 years. Whether this was cerebellar or vestibular in origin is not known.

\section{Discussion}

In two recent reports attention was drawn to the occurrence of persistent CSF abnormalities after apparently adequate treatment of meningitis (Chartrand and Cho, 1976; Jacob and Kaplan, 1977). One-third of the patients with haemophilus meningitis in this survey had CSF white blood counts $>0.050 \times 10^{9} / 1$ after adequate treatment. This pleocytosis was not associated with a longer clinical illness or with more complications. Nor did it presage a higher incidence of sequelae. It was related to the initial CSF white blood count and glucose content.

The CSF white blood count at diagnosis is not related to the CSF bacterial content (Feldman, 1976). It is, however, an indicator of the patient's response to infection. Also, the CSF glucose level in meningitis is related to brain metabolism and the degree of meningeal inflammation rather than to the CSF bacterial content (Menkes, 1969). Thus, persistent pleocytosis may indicate a better inflammatory response by the patient.
In the series of haemophilus and pneumococcal meningitis reported by Chartrand and Cho (1976), sequelae were present in one of 13 patients with persistent pleocytosis, whereas they were found in 3 of 15 patients without such pleocytosis. This tendency to fewer sequelae if persistent pleocytosis is present is also shown in the present survey. Thus, persistent pleocytosis may be a good prognostic finding. A recent report (Lindberg et al., 1977) had suggested that chloramphenicol with ampicillin may result in more sequelae. Of 22 patients with haemophilus meningitis treated with both antibiotics in this series, none had sequelae.

When clinically indicated, a lumbar puncture is mandatory. Even if it is clear a second lumbar puncture may be indicated within a few hours (Rapkin, 1974). Repeat lumbar punctures may also be warranted at any stage during treatment if indicated by the clinical condition. However, a lumbar puncture after 10 to 14 days in this series did not contribute any useful information from the patients' point of view; for instance, no case of relapse or failure to sterilise the CSF was found. On the contrary, it tended to result in longer treatment and more time spent in hospital. A lumbar puncture may also be hazardous. Thus, in a clinically well child who has received 10 days of appropriate antibiotic treatment, routine performance of a lumbar puncture is not justified.

I wish to thank Dr P. Deasy for his helpful advice and Mrs A. McAlinden for her patience.

\section{References}

Chartrand, S. A., and Cho, C. T. (1976). Persistent pleocytosis in bacterial meningitis. Journal of Pediatrics, 88, 424-426.

Feldman, W. E. (1976). Concentrations of bacteria in cerebrospinal fluid of patients with bacterial meningitis. Journal of Pediatrics, 88, 549-552.

Jacob, J., and Kaplan, R. A. (1977). Bacterial meningitis. American Journal of Diseases of Children, 131, 46-48.

Lindberg, J., Rosenhall, U., Nylen, O., and Ringner, A. (1977). Long-term outcome of Hemophilus influenzae meningitis related to antibiotic treatment. Pediatrics, 60, 1-6.

Menkes, J. H. (1969). The causes for low spinal fluid sugar in bacterial meningitis: another look. Pediatrics, 44, 1-3.

Rapkin, R. H. (1974). Repeat lumbar punctures in the diagnosis of meningitis. Pediatrics, 54, 34-37.

Shinefield, H. R. (1975). Bacteremia, lumbar punctures, and meningitis. American Journal of Diseases of Children, 129, 547-548.

Smith, D. H., Ingram, D. L., Smith, A. L., Gilles, F., and Bresnan, M. J. (1973). Bacterial meningitis: a symposium. Pediatrics, 52, 586-600.

Correspondence to Dr K. D. Connolly, Paediatric Department, Portiuncula Hospital, Ballinasloe, Co. Galway, Eiré. 